\title{
REALISMO E HISTORIA
}

\author{
REALISM AND HISTORY \\ PAULO CÓRDOBA \\ Universidad del Rosario, COLOMBIA \\ cordoba.guzman1994@gmail.com
}

\begin{abstract}
This article argues that the reality principle must be accepted as a necessary condition for any adequate historical research. The first part explores the arguments of the hermeneutical realism, in order to rescue some of them and showing their importance for the historical theory. The second part reconstructs a debate between historical theory, literary theory, linguistic turn and hermeneutical realism, aiming to expose the risks of anti-realism for the historical discipline. At the end, it is expected to present a perspective that points out what is the meaning of rescue realist elements that supports a not arbitrary historical research.
\end{abstract}

Keywords: Realism $\bullet$ anti-realism $\bullet$ truth $\bullet$ historical theory $\bullet$ literary theory $\bullet$ situation

\section{Introducción}

El reconocimiento del horizonte situacional del historiador, de la situación desde la cual piensa el intérprete de la historia, es un tema que ha suscitado incontables debates en torno al problema de la verdad. Aún en la actualidad, llama considerablemente la atención el hecho de que se sigan intentando sostener tesis que apuntan a homologar teóricamente los objetos de estudio de la Historia ${ }^{1}$ y la literatura, como si ambas disciplinas estuvieran gobernadas por los mismos presupuestos en torno al problema de la verdad. Sin embargo, y por fortuna, algunos de los más destacados teóricos de la historia han salido a enfrentar este tipo de pretensiones anti-realistas, demostrando que en el trasfondo de ellas descansan problemas tanto epistemológicos como morales.

Uno de los teóricos más destacados por intentar llevar a cabo esa homologación entre la disciplina histórica y la literaria es Hayden White (1990, p.2), y uno de los historiadores más destacados por enfrentarse a la postura de White es Carlo Ginzburg. Por tal razón, una parte de este artículo se sumergirá en el debate entre estos dos autores; mas no para aportar renovados argumentos a favor de la crítica al problema de la homologación Historia/literatura, que ya ha merecido considerables esfuerzos; ${ }^{2}$ sino para profundizar en el problema de la verdad histórica, y así reforzar la tesis sobre lo improcedente que resulta escribir historia, re-construir el 
pasado, ignorando directa o indirectamente el principio de realidad que debería regir toda investigación científico-espiritual. ${ }^{3}$

Este esfuerzo acude principalmente a los avances epistemológicos logrados en el marco de la hermenéutica filosófica, puesto que en ese campo han surgido considerables aproximaciones al problema de la realidad que han desembocado en nuevos modelos de realismo, ${ }^{4}$ según los cuales es posible mostrar que, aunque nuestro conocimiento de las cosas esté siempre mediado por nuestra situación histórica, a partir de ello no se puede afirmar que resulta imposible decir verdades sobre las cosas o peor: que seamos capaces de inventarnos la realidad por medio del lenguaje o de cualquier otro medio que esté a nuestro alcance como seres humanos.

Estos dos puntos de partida permiten evidenciar que la presente investigación se mueve entre las disciplinas histórica y filosófica, tratando de trazar un diálogo entre ambas. A pesar del reto que este objetivo presenta, se puede llegar a considerar que tanto la filosofía como la historia son campos del pensamiento que no pueden desligarse uno de otro, si lo que se busca es una mejor aproximación al problema de la realidad. Por tanto, a continuación se presentará un texto que apunta a esto último y que se divide en dos momentos: 1) la exploración de los argumentos desarrollados en el terreno del enfrentamiento entre realismo hermenéutico y anti-realismo, con la finalidad de recuperar algunos presupuestos realistas necesarios para una defensa de la realidad como condición necesaria de la teoría histórica; y 2) la reconstrucción del debate entre teoría literaria y teoría histórica, donde los postulados del giro lingüístico y del realismo hermenéutico encontrarán un terreno adecuado para su enfrentamiento.

Al final, el objetivo definitivo de este esfuerzo es mostrar la relevancia de una teoría histórica basada en elementos realistas, capaces de garantizar una investigación responsable sobre el pasado, es decir, capaces de garantizar una historiografía basada en acontecimientos pretéritos verdaderos. En ese sentido, la cuestión central que guiará toda esta propuesta es la siguiente: ¿cómo es posible defender el realismo como una condición necesaria para la investigación histórica?

\section{Realismo hermenéutico}

\subsection{Rescate del principio de realidad}

La contribución de Carlos Miguel Gómez Rincón al problema de la verdad, en el marco de la hermenéutica filosófica, dejó abierta una ventana de oportunidad para extrapolar las reflexiones de este autor y sus referentes desde la filosofía hasta la Historia. En su artículo titulado «Historicidad, realismo y verdad», Gómez se sumerge en el debate sobre la interpretación del llamado axioma hermenéutico, con el fin de descubrir cuál de las partes enfrentadas triunfa en materia epistemológica. 
El axioma hermenéutico señala que toda realidad es realidad-interpretada. De esta afirmación surgieron dos posturas contrarias. La primera es de corte realista y defiende que, si bien toda realidad es siempre interpretada, interpretar es interpretar una realidad externa al intérprete. La segunda, sin embargo, es radicalmente antirealista en tanto que intenta defender que el axioma hermenéutico parece señalar otra cosa: interpretar es inventar una realidad (Gómez Rincón 2017, p.79). Partiendo de este enfrentamiento entre realismo y anti-realismo, Gómez se esfuerza por reforzar la primera postura del debate y criticar la segunda.

Así las cosas, el autor defiende la tesis que sostiene que toda perspectiva, todo punto de vista sobre el mundo, a pesar de ser inevitablemente histórico, no constituye un obstáculo infranqueable al momento de perseguir verdades sobre las cosas con las que estamos en contacto permanente. Al contrario, la perspectiva es una suerte de medio para llegar a dicho objetivo (Gómez Rincón 2017, pp.77-8). Esta tesis presupone dos cosas: 1 ) que existe una realidad externa al intérprete sobre la cual él puede afirmar verdades, a pesar de encontrarse fuertemente influenciado por la historia que lo atraviesa; y 2) que la postura que asume que interpretar es inventar la realidad yerra al otorgarle demasiada capacidad creadora al ser humano.

En torno al segundo punto, Gómez (2017, pp.82-3) muestra que la postura antirealista lo único que hizo fue reemplazar una tesis problemática por otra. Específicamente hablando, los anti-realistas primero abandonaron la tesis de un pensador como Nicolás De Cusa, quien afirmaba que el ser humano solo podía alcanzar verdades sobre el mundo gracias a que Dios se lo permitía mediante su poder divino. ${ }^{5}$ Luego, una vez relegada la perpectiva de De Cusa, los mismos anti-realistas procedieron a reemplazarla por la tesis que enaltece la supuesta potencia creadora que caracteriza al ser humano, defendida por un pensador como Friedrich Nietzsche en sus años de juventud. ${ }^{6}$

Este reemplazo de una tesis poco convincente por su carácter teológico desbordado, por otra aún menos convincente debido a su antropocentrismo exacerbado, muestra muy bien la improcedencia de la interpretación anti-realista en torno al axioma hermenéutico, y deja abierta la posibilidad de seguir reforzando su contraparte en el debate sobre la verdad.

En ese sentido, Gómez (2017, p.85) se empeña en mostrar que la postura realista puede ser reforzada por medio de los aportes de un pensador como John Searle, para quien la presuposición de la realidad es la condición de inteligibilidad de la comunicación, puesto que el lenguaje solo funciona en la medida en que se refiere a una realidad independiente (exterior). No obstante, Gómez reconoce que el argumento de Searle es insuficiente para una defensa de la realidad exterior, pues intenta defender tan solo la "realidad pública" (la realidad compartida) de la que necesita el lenguaje para tener sentido. En consecuencia, si lo que se busca es defender una tesis que señale la relevancia y necesidad de la realidad exterior para el ser humano, 
entonces

el reto al que debe responder un argumento a favor del realismo no concluye con una defensa de la referencia lingüística, sino con la defensa de que aquello a lo que nos referimos tiene un modo de ser independiente de nuestras prácticas discursivas y formas de actuar en el mundo que además debe poder ser captado, al menos parcialmente y desde cierta perspectiva, por ellas (2017, pp.87-8).

Esto último, en resumidas cuentas, quiere decir que no solo es necesaria la realidad para poder decir cosas inteligibles sobre ella; sino que la condición de verdad de lo dicho depende de la realidad a la cual ello se refiere, es decir: depende del modo de ser de las cosas sobre las cuales habla el lenguaje (Gómez Rincón 2017, p.89). O expresándolo en palabras técnicas: se puede afirmar que la realidad ontológicamente objetiva condiciona cualquier interpretación sobre ella, en tanto que permite evaluar si una interpretación es verdadera o no, es decir, si una interpretación descubre algo sobre el mundo y plantea cosas adecuadas sobre él. Al reconocimiento de esta relación evaluable entre realidad e interpretación es a lo que se denominará principio de realidad a lo largo de todo este texto.

La relación unidireccional realidad-interpretación hasta aquí presentada, sin embargo, no puede ser comprendida por fuera los postulados básicos de la teoría hermenéutica de Martin Heidegger y Hans-Georg Gadamer. Por tal motivo, resulta necesaria una reconstrucción de la estructura heideggeriana de la realidad, en primer lugar, y una reconstrucción de la teoría gadameriana sobre la distancia temporal como condición de la comprensión, en segundo lugar. Todo con el fin de mostrar cuáles son los cimientos teóricos desde los cuales se erigieron investigaciones como las de Gómez, y cómo resulta posible seguir teorizando sobre la historicidad humana.

\subsection{Relación entre realidad e interpretación}

Como bien lo explica el artículo de Carlos Miguel Gómez Rincón, “[1]ejos de ser una materia bruta no interpretada, carente de todo carácter y determinación, maleable al extremo de la irrelevancia, la realidad tiene un modo de ser que se impone y exige ser reconocido en nuestros tratos habilidosos con el mundo" (2017, p.92). Esta tesis evidentemente realista parte de la teoría heideggeriana de la existencia, dentro de la cual la cuestión de la realidad está necesariamente ligada al problema del mundo exterior: "el análisis de la «realidad» sólo es posible sobre la base del adecuado acceso a lo «real»" (Heidegger 2014 [1927], §43, p.222).

A juicio de Heidegger, la cuestión de la existencia del mundo y su comprobación carece totalmente de sentido, puesto que el mundo se presupone ya-ahí antes de entrar en contacto con él, antes de movernos habilidosamente en él, sea en el trato 
práctico con los objetos, sea en el referirse adecuadamente sobre algo a través de medios puramente lingüísticos. En consecuencia, "[s]usceptible de ser descubierto tampoco lo es, empero, lo «real» sino sobre la base de un mundo ya abierto [presupuesto y con sentido]. Y sólo sobre esta base puede lo «real» seguir oculto" (2014 [1927], $\S 43$, p.223. Cursivas originales). Toda prueba - o intento de prueba - del mundo exterior es, por tanto, y en contra de lo reclamado por Immanuel Kant, ${ }^{7}$ absurda. "El «ser ahí» [Dasein] bien comprendido se resiste a tales pruebas" (Heidegger 2014 [1927], §43, p.226), en tanto que él — nosotros — nos encontramos ya arrojados en una vida presuponiendo que el mundo que nos circunda existe sin necesidad de que nadie lo demuestre. Y para poner un ejemplo: nadie que haya intentado comprender partiendo de la duda metódica cartesiana, creyendo ciegamente que lo llevaría a algún puerto seguro, podría afirmar que salió bien librado.

El problema de la duda metódica es, precisamente, que mediante el dudar absoluto se llega inclusive a dudar de la existencia de sí-mismo (Descartes $C P$, Primera Meditación, A-T, IX, p.169), ${ }^{8}$ cayendo en un absurdo tan cercano a la irrelevancia que la omisión de este tipo de "método dubitativo", más que resultar una posibilidad, termina siendo un camino bastante seguro. Por eso es que la ontología heideggeriana señala la necesidad básica de presuponer la realidad -y en un sentido mucho más preciso, el mundo- en la vida del Dasein que siempre está buscando comprender el contexto en el cual se mueve (Heidegger 2014 [1927], §9, p.55).

Así pues, en el sendero trazado hasta aquí, se puede expresar en términos técnicos que mundo es siempre mundo-con-sentido, mundo-abierto y mundo-presupuesto; pero también mundo-resistente, esto es, mundo que se resiste a ser descubierto (Heidegger 2014 [1927], §43, pp.231-2). Como ya lo había dicho Heráclito: "la naturaleza aprecia el ocultarse" (D-K, 22, B 123), ${ }^{9}$ y esa es la razón por la cual fue muy ilustrativo que Heidegger nos enseñara que la verdad debe ser siempre arrebatada de las "cosas mismas" (Gadamer 2015b, p.52).

El tránsito filosófico del terreno de la "cosa en sí" kantiana al terreno hermenéutico de las "cosas mismas", para encontrar el topos adecuado en el cual emprender cualquier intento de búsqueda de la verdad, fue decisivo para la filosofía de Heidegger (Estrada 2018, p.29). El que busca comprender e interpretar, señala Gadamer (2012 [1960], pp.332-6) en su interpretación del numeral 32 de El ser y el tiempo, de Heidegger, debe estar abierto y atento al enfrentamiento entre sus propias presuposiciones y "lo dicho" por las cosas mismas. Con estas palabras se abren cuestionamientos importantes en torno al problema de la verdad dentro de la tradición hermenéutica iniciada en la Alemania del siglo pasado: ¿qué significa propiamente "cosa misma"? ¿Cuál es la diferencia entre comprender e interpretar? Y ¿cómo es posible arrebatarles la verdad a las cosas mismas por medio de la comprensión, para llegar a una interpretación adecuada sobre ellas? Responder a estas preguntas implica dos cosas: reconstruir la estructura de la pre-comprensión y la estructura de la 
comprensión de Heidegger, y mostrar cuál es el concepto de verdad sobre el cual se centra su teoría hermenéutica.

Ante todo, es preciso iniciar resaltando que con el término técnico "cosa misma" se busca hablar, en hermenéutica, de todo aquello que condiciona nuestras prácticas lingüística o no-linguüísticas. Las cosas mismas, en términos puramente lingüísticos, sin embargo, son todos los temas sobre los cuales hacemos afirmaciones en tanto seres preocupados por la comprensión. Por ende, ejemplos de cosas mismas son: objetos materiales particulares con los que podemos entrar en contacto físico, sobre los que podemos afirmar cosas que pueden ser verdaderas o falsas, o incluso se trata de temáticas relacionadas con mundos fantásticos que en alguna medida hablan o sugieren reflexiones sobre algo real que afecta a la humanidad de cada quien y, por tanto, pueden ser evaluadas en términos de verdad o falsedad. Con las conjeturas hermenéuticas que se presentarán a continuación se podrá comprender mejor esta aseveración. Por ahora, queda resuelta la primera cuestión acerca de qué se habla cuando se habla de "cosa misma" en hermenéutica: se trata de temas (cosas) evaluables para descifrar su condición de verdad.

Ahora bien, emprendiendo una reconstrucción de la teoría heideggeriana de la comprensión, es menester mencionar que ésta describe tres elementos previos de todo comprender: 1) la presuposición de la existencia de un mundo previo (Vorhaben), el cual precede a la existencia humana y a nuestras posibilidades comprensivas; 2) una perspectiva previa sobre el mundo precedente (Vorsicht), esto es, un punto de vista previo determinado por la historia que atraviesa a quien busca comprender; y 3) un concepto previo sobre el mundo (Vorgriff), es decir, una interpretación a la cual ha llegado quien comprende por vía de su propia experiencia, por vía de sus prejuicios y sus contactos previos con el mundo que lo circunda (Gadamer 2015a, pp.83-4). A este conjunto de elementos previos para la comprensión es a lo que Heidegger llama estructura de la pre-comprensión (2014 [1929], §32, pp.166-8).

A partir de esta estructura es que Heidegger logra trazar su estructura de la comprensión, según la cual todo comprender adecuado solo es posible cuando: 1) se asume la existencia de un mundo-con-sentido que se encuentra ya-ahí, previamente a los intentos de búsqueda de la verdad por parte de un ser humano o Dasein cualquiera; 2) ese sentido del mundo puede ser captado por medio de la comprensión, lo cual indica que comprender es captar un modo de ser de las cosas, aunque el ser humano se encuentre inevitablemente influenciado por un sistema de prejuicios y un lenguaje que le han sido legados, que él ha heredado por cuenta de la historia que lo atraviesa en tanto perteneciente a una sociedad determinada; y 3) lo captado puede ser interpretado o - lo que es lo mismo - apropiado y traducido por vías como el lenguaje para evidenciar que se ha logrado comprender algo (2014 [1929], §32, pp.169-70). Acorde a esto, es posible observar que la respuesta a la segunda cuestión - que busca aclarar cuál es la diferencia entre comprender e interpretar - es la siguiente: la 
comprensión es captar el modo de ser de las cosas y la interpretación es una suerte de aclaración, por vías como el lenguaje, de ese modo de ser de las cosas mismas.

Finalmente, para dar respuesta a la pregunta que cuestiona por cómo es posible arrebatarles la verdad a las cosas mismas mediante comprender e interpretar, es necesario aclarar cuál es el concepto de verdad que subyace en el trasfondo de la teoría heideggeriana de la comprensión. Al respecto, se puede señalar que en la estructura de la comprensión de Heidegger descansa un tipo de verdad que dicho pensador sustrajo de la remota cosmovisión griega para cimentar las bases de su propia filosofía de la existencia: la verdad entendida como aletheia. Se trata de un concepto que se refiere al des-ocultamiento y denota el hecho de que la verdad nunca esté "a la vista" de quien busca comprender. Por consiguiente, si la naturaleza precia el ocultarse, como sostenía Heráclito, entonces eso quiere decir que siempre es necesario descubrir el lugar en dónde se oculta la verdad si lo que se busca es una comprensión adecuada de la realidad (Heidegger 2014 [1929], §44, pp.240-1 y 243), esto es lo que hace del ser humano un ser-descubridor y a la vez condensa la verdad y la realidad en una sola cosa. En ese sentido, se puede afirmar que - hermenéuticamente hablando ser verdadero (des-ocultante) es ser real.

Esta homologación verdad-realidad lograda por Heidegger, a través de la recuperación del concepto griego de aletheia, permite además señalar que la llamada verdad por correspondencia, asumida mucho tiempo como la forma básica y originaria de la verdad, no es más que una derivación de un concepto mucho más antiguo, como es el caso de la aletheia o des-ocultamiento.

El propio Heidegger se encargó de mostrar que, aunque Aristóteles subrayó que la verdad también descansa en los juicios sobre las cosas (2014 [1929], §44, pp.2356), el estagirita nunca defendió la tesis que sostiene que el lugar original de la verdad fuese el juicio (ese, en realidad, no fue más que un prejuicio inadecuado procedente del tomismo medieval); antes bien, el lugar de la verdad está en las cosas mismas sobre las que actúa el carácter de descubridor o encubridor del ser humano (2014 [1929], §44, p.247). Por eso, cuando Gadamer (2015b, pp.53-4) profundizó en este hallazgo de Heidegger, hizo particular énfasis en el hecho de que el mismo ser humano que busca des-ocultar la verdad a través de herramientas como el lenguaje, muchas veces también puede terminar ocultándola por medio del uso irresponsable de ese mismo lenguaje, lo cual hace de él un ser tan encubridor como descubridor. Pero esto lo que indicó, para la tradición hermenéutica que empezaba a cobrar forma en la Alemania del siglo pasado, fue que la búsqueda de la verdad - de la captación de la realidad y su aclaración por medio de la interpretación — es una tarea tan ardua como interminable; aunque factible de llevarse a cabo en tanto que somos seres orientados hacia la verdad y dotados de capacidades como el lenguaje que nos permiten ser "mostradores" de ella, aún cuando siempre estemos condenados a alcanzarla tan solo parcialmente. 
Hasta aquí, entonces, queda claro que la comprensión es el medio a través del cual resulta posible arrebatarles verdades a las cosas mismas, y la interpretación es la vía mediante la cual hacemos "visible" tales verdades. Empero, surge una pregunta de gran importancia para efectos de esta investigación y es la siguiente: ¿cómo es posible comprender aquello que se encuentra temporalmente distante de nosotros, sin renunciar al principio de verdad/realidad en medio de tal esfuerzo? Este cuestionamiento es de tipo histórico y su resolución fue propuesta por Gadamer en su teoría de la comprensión, por lo que resultará de gran ayuda reconstruir algunos de sus postulados con miras a perfilar esta argumentación hacia una reflexión sobre el problema del realismo en la disciplina que estudia el pasado, es decir, en la Historia.

\subsection{Relación entre realidad y distancia temporal}

El problema de la distancia en el tiempo siempre ha sido una preocupación propia de los historiadores. Al menos de aquellos que no se centran solamente en los acontecimientos que tienen lugar en su propia época. Dicha preocupación prevalece sobre todo porque su objeto de investigación es aquello que realmente sucedió en el pasado (Gadamer 1997, p.105).

Durante la celebración del octogésimo quinto aniversario de Gadamer en Heidelberg, el historiador alemán Reinhart Koselleck presentó una ponencia donde resaltó que el eje central de la obra principal de Gadamer, Verdad y Método, era precisamente esa relación entre la hermenéutica y el tiempo, entre el arte de comprender y el horizonte situacional del Dasein "comprensor". En aquel planteamiento no había ningún equívoco.

Koselleck (1997, p.68) quería señalar que — para el proyecto hermenéutico gadameriano - todo comprender está vinculado, por principio, al tiempo, a la situación de quien busca comprender y tiene plena conciencia de que en él mismo, en el comprensor, se condensan presente, pasado y futuro, determinándolo como ser humano, guiándolo en su transitar por el mundo. Es esa condensación temporal lo que hace del proyecto de Gadamer (2003, p.43) un esfuerzo que también apunta a mostrar cómo es posible un diálogo entre el presente y el pasado (Bloch 2001 [1949], p.38).

Fue en el marco de ese mismo diálogo entre lo sucedido y la situación de quien busca comprender lo sucedido, que surgió la propuesta que sostiene que la distancia en el tiempo no debe ser vista como una limitación para la comprensión; sino que más bien se trata de una oportunidad en el camino hacia la verdad (Gadamer 2012 [1960], p.367). En otras palabras, esto quiere decir que la distancia temporal no constituye tanto un abismo para la comprensión; sino que la posibilita en la medida en que podemos acudir a la tradición, al universo de presuposiciones, prácticas y creencias de una sociedad determinada, para descifrar lo que nos quiere decir aquello que se encuentra temporalmente apartado de nosotros. ${ }^{10}$ 
Con esta propuesta, tanto Heidegger como Gadamer lograron desplazar el principio científico-natural de la "distancia respecto al objeto", imperante en el ámbito de las llamadas Ciencias del Espíritu, y — gracias a ello - obtuvieron el motor que impulsó sus teorías de la comprensión hasta el punto al que llegaron, pues el principio de la distancia temporal no solo tiene en cuenta que toda comprensión es siempre situada; sino que también toda comprensión está siempre en permanente movimiento.

La aparición de cada nueva perspectiva adecuada sobre la humanidad posibilita la aparición de nuevos prejuicios que estén en condiciones de guiarnos por el camino hacia la verdad, lo cual indica que, en efecto, estamos condenados a permanecer siempre en un sistema de prejuicios que guía nuestra comprensión. No obstante, esto no quiere decir que la verdad -o la realidad- no pueda hacer absolutamente nada en contra de lo que pensamos sobre ella antes de entrar en contacto con-ella, es decir, en contra de nuestros prejuicios; ni que nuestros prejuicios sean siempre falsos (esta idea fue un legado absurdo que nos dejó la Ilustración); antes bien, cuando se habla de prejuicios en hermenéutica se hace referencia a aquellos juicios previos sobre la realidad que pueden ser confirmados o refutados por medio del contacto con las cosas mismas (Gadamer 2012 [1960], p.337). Y es en este punto donde la distancia en el tiempo cobra el valor que Gadamer le otorgó con tanto ahínco.

La hermenéutica gadameriana mostró muy bien que la distancia temporal es la que hace posible distinguir entre prejuicios adecuados e inadecuados para la comprensión. Por tal razón, la afirmación que señala que la conciencia hermenéutica debe ser también una conciencia histórica tiene mucho sentido, puesto que ella, la conciencia hermenéutico-histórica, debe siempre apuntar al objetivo de hacer evidentes sus propios prejuicios con el fin de permitir que la tradición le "hable" para guiarla en su búsqueda de la verdad (Gadamer 2012 [1960], pp.368-9). Pero ¿qué es exactamente la tradición? ¿Cuál es la definición técnica de este concepto que emplea Gadamer constantemente en Verdad y Método?

El concepto de tradición resulta particularmente útil cuando se pretende llegar a comprender un poco el pasado, y su definición, de hecho, es de corte histórico: un universo de sentido, esto es, un conjunto de prejuicios que surgieron en algún momento en el seno de sociedades humanas y que se conservaron - transformándose o preservándose - a pesar del trasegar del tiempo (Gadamer 2012 [1960], p.349).

Ahora bien, es preciso señalar que, en hermenéutica, cuando se habla de tradición, no se hace referencia a un conjunto de prejuicios históricos que se imponen por vía de la aceptación pasiva o por vía de la violencia; sino que se habla de una serie de prejuicios que han ganado su legitimidad, su autoridad, a partir del hecho de que se adecúan a las cosas mismas y descubren las verdades que en ellas se ocultan. Por tanto, resulta evidente que la idea de autoridad de la tradición de Gadamer no tiene nada que ver con 
un acto de sumisión y de abdicación de la razón, sino [con] un acto de reconocimiento y de conocimiento: se reconoce que el otro [en este caso el otro-de-la-tradición] está por encima de uno en juicio y perspectiva y que en consecuencia su juicio es preferente o tiene primacía respecto al propio. [... Este sentido rectamente entendido de autoridad no tiene nada que ver con obediencia ciega de comando. En realidad no tiene nada que ver con obediencia sino con conocimiento (Gadamer 2012 [1960], p.347).

Comprendiendo este argumento es posible ver que la autoridad de la tradición no parte de lo arbitrario o lo autoritario; sino que, por el contrario, ella, la tradición, busca legitimar su autoridad en lo verdadero o real del mundo. Ese fue uno de los grandes legados que nos dejó el romanticismo alemán: mostrar que la tradición conserva algún derecho, algunas verdades, y por eso determina considerablemente nuestras instituciones y nuestros comportamientos (Gadamer 2012 [1960], pp.348-9).

Una de las premisas básicas de la hermenéutica gadameriana es que "[e]n realidad no es la historia la que nos pertenece, sino que somos nosotros los que pertenecemos a ella" (Gadamer 2012 [1960], p.344). Y un antiguo proverbio árabe que el historiador Marc Bloch solía citar a menudo parece confirmar esta premisa: "Los hombres se parecen más a su tiempo que a sus padres" (2001 [1949], p.64). Este presupuesto de pertenencia a la historia, a la situación de estar a la vez marcados por un pasado y un presente determinados e interconectados, es lo que legitima la fuerza de un concepto como el de tradición defendido por Gadamer.

Gadamer tenía bastante claro el hecho de que todo ser humano comprende siempre desde una posición histórica determinada, desde una tradición o lo que es lo mismo: desde un conjunto de prejuicios legados entre generaciones con el paso del tiempo. Esto se deriva de la alteración hecha por Martin Heidegger al concepto de círculo hermenéutico: si bien este concepto técnico emergió por cuenta de Friedrich Schleiermacher como un principio metódico de la hermenéutica (comprender un texto implica comprender las partes por el todo y el todo por las partes); con Heidegger (2014 [1927], §32, p.171), sin embargo, adquirió un significado ontológico novedoso según el cual comprender es siempre remitirse a formas previas de comprensión, puesto que toda comprensión implica siempre partir de prejuicios que son los primeros guías del ser humano en su constante transitar por el mundo.

Con base en esto, es posible comprender por qué para Gadamer (2012 [1960], pp.336-7; 2015c, p.241) la tradición aparece como algo inevitable que siempre debe estar en proceso de evaluación y no en proceso de destrucción epistemológica, lo cual quiere decir que esa inevitabilidad de la tradición no implica que ella misma no pueda sufrir cambios a lo largo de la historia. Al contrario, el hecho de que los seres humanos estemos siempre inmersos en tradiciones deja abierta la posibilidad de que ellas puedan ser asumidas como ejemplares o como aborrecibles (Gadamer 
2012 [1960], p.350), dignas de apropiación, de transformación o simplemente de rechazo por parte de quienes están frente a ellas. Esto sin duda alguna termina minando la crítica de Albrecht Wellmer, retomada por Habermas, en la que se señala que la tradición es un lugar tanto de "verdad posible y acuerdo fáctico" como de "no verdad fáctica y de la perpetuación del poder" (Citado en: Habermas 1996, p.301). De hecho, esa es la razón por la cual resultó indispensable acudir a la interpretación que hace Gadamer del concepto de autoridad de la tradición, pues con él se puede aclarar el sentido de un término técnico que no es en lo más mínimo estático, ni opresivo, ni anti-epistemológico, ni nada por el estilo.

A diferencia de lo que piensan infundadamente muchos de los críticos de Gadamer, como Habermas, la tradición no debería verse como un obstáculo para la comprensión, sobre todo porque ella es, indudablemente, el único camino mediante el cual se puede reducir la distancia temporal entre quien busca comprender el pasado y el pasado mismo. En ese sentido, la destrucción de la tradición - si es que algo así resulta siquiera pensable - o la renuncia al hecho de acudir a ella para comprender el pasado, constituiría la destrucción de una suerte de puente que conecta algo tan simple como el oficio del historiador con su objeto de estudio. Y esto representaría el fin de cualquier intento por comprender al ser humano en la dimensión que le es más propia: su historicidad.

\subsection{Historicidad como puente hacia la realidad}

Hasta este punto se han reconstruido los postulados de la teoría hermenéutica para mostrar sobre todo cómo debe ser comprendida la realidad, y por qué es tan importante conservar una interpretación sobre ella que la reconozca como una condición de sentido para comprender el mundo de la vida, el mundo del Dasein. En este segmento, empero, se abordará brevemente el concepto de historicidad para definirlo y mostrar cómo contribuye a la comprensión humana.

Como ya se ha mencionado con antelación, el acceso a la realidad solo es posible por medio de nuestras interpretaciones impulsadas por prejuicios; aún si ellas no la inventan. "De este modo, nuestros sistemas interpretativos y prácticas cognitivas son un modo de contacto con lo real, y no un muro que nos separa de ello y nos encierra auto-referencialmente" (Gómez Rincón 2017, p.91). Esto quiere decir que es la historicidad que nos atraviesa la encargada de permitirnos entrar en contacto con lo real, pues nuestros "sistemas interpretativos" y nuestras "prácticas cognitivas" provienen de nuestra historia. No obstante, cabe preguntar ¿qué significa propiamente historicidad en el ámbito de la hermenéutica contemporánea? Responder a esta cuestión permitirá clarificar uno de los conceptos más importantes para efectos de cualquier investigación hermenéutico-histórica.

Por historicidad se entiende el modo de ser del Dasein según el cual éste se en- 
cuentra siempre en una situación histórica (tradición), y en constante transformación por medio de una cierta apertura a la historia, esto es, por medio de una apertura a las realidades pasadas y presentes que le permiten proyectarse situaciones a futuro (Gómez Rincón 2017, pp.92-3).

La historicidad, en este sentido, es el gran puente que permite a los seres humanos entrar en contacto con la realidad, pues parece claro que a través de ella resulta posible comprender cómo es que el presente ha llegado a ser lo que es. Ya lo decía una frase de Roger Chartier: "Si bien los historiadores fueron siempre los peores profetas, sí pueden sin embargo ayudar a comprender las herencias acumuladas que hicieron de nosotros lo que hoy somos" (2007, p.16). Con ello, Chartier lo único que hizo fue poner de relieve, de una forma muy precisa y certera, la manera como la historicidad del ser humano permite comprender mejor la realidad.

Pero esta aseveración acerca de los historiadores hace algo más que clarificar uno de los objetivos del oficio del investigador del pasado: muestra que la pregunta por la relación entre Historia y realismo hermenéutico es profundamente necesaria, debido principalmente al hecho de que el objeto de estudio del historiador, el pasado, a pesar de su complejidad, es uno de los senderos más seguros para avanzar en el camino hacia la comprensión del objeto de estudio del hermeneuta realista, es decir, para la comprensión de la realidad que condiciona la interpretación. El historiador, entonces, aparece así como el guía del hermeneuta en el viaje de exploración de la realidad y, por ende, su compromiso y responsabilidad para llegar a la verdad de las cosas mismas debe resultar inigualable.

\section{Historia, teoría literaria, giro lingüístico y realismo hermenéutico}

\subsection{Historia y teoría literaria}

A pesar de que hasta el momento se han trazado algunos argumentos relevantes para defender la necesidad del realismo dentro de cualquier investigación histórica, y visceversa; lo cierto es que no siempre se presupone esa necesidad para guiar el avance del investigador que busca descifrar algo sobre el pasado. Y esto es bastante común en el marco de algunas perspectivas que consideran a la historiografía, a la escritura de la historia, como una práctica sobre todo de invención lingüística y narrativa que crea realidad. Entre este tipo de posturas, destaca principalmente la del teórico estadounidense Hayden White.

Un texto que critica el punto de vista de White, para defender el principio de realidad en el marco de la historiografía, es "Unus testis. El exterminio de los judíos y el principio de realidad", del historiador italiano Carlo Ginzburg. Allí el autor parte 
de un análisis del principio jurídico del derecho romano, unus testis, según el cual un solo testigo es insuficiente para llegar a cualquier veredicto (Ginzburg 2014b, p.302). Este principio se fortaleció considerablemente debido a que nació y se desarrolló en el seno de las tradiciones judaica y romana. Sin embargo, Ginzburg (2014b, p.303) plantea una crítica muy acertada al principio jurídico del unus testis para mostrar su improcedencia en el marco de la historiografía: si bien es cierto que en Historia se cotejan diversas fuentes para evaluar la verdad del testimonio; en ocasiones un solo testigo basta para cambiar ideas decisivas sobre el pasado.

Ciertamente, ningún historiador comprometido con la transparencia de su oficio podría negar que la investigación histórica debe seguir un proceso muy parecido al de una investigación judicial, en la cual prueba, verdad e historia son momentos estrecha y secuencialmente vinculados que permiten avanzar hacia el conocimiento del pretérito. Empero, aún cuando el proceso historiográfico puede asemejarse a un proceso judicial, un principio como el unus testis sería menos que inútil para la investigación histórica. Y esto es así debido a la naturaleza de la pregunta histórica.

Johann Gustav Droysen fue uno de los primeros teóricos de la historia en presentar una reflexión certera sobre este asunto. Para Droysen, la pregunta histórica solo puede plantearse a partir de un conocimiento previo del pasado que se entremezcla con una sospecha en torno al mismo, en torno a la legitimidad de lo que sabemos o creemos saber. Por tal motivo, la pregunta histórica muchas veces nos mueve a la investigación. Pero "[é]ste es un largo y difícil camino. Con la pregunta histórica tenemos solo una posibilidad, un destello en nuestra alma, una esperanza. De lo que se trata es de si realmente el asunto es así como lo presentimos al preguntar, si es posible demostrarlo" (Droysen 1983 [1937], §19, p.46).

Es precisamente en el sospechar que precede a la pregunta histórica en donde encuentra un lugar privilegiado el testigo (incluso si es único) del pasado, cuya experiencia puede cambiar el rumbo de las interpretaciones sobre los acontecimientos pretéritos. Lo que hizo Droysen con su reflexión metódica fue mostrar que, en el arduo camino de la investigación histórica, es necesaria una apertura frente a lo que tiene el otro - en este caso el-otro-de-la-historia - para decirle al historiador y guiarlo en su trayectoria de exploración del pasado. Por consiguiente, a patir de esto, se puede evidenciar que la secuencia prueba-verdad-historia, que se sigue respetando aún en la actualidad dentro de las operaciones historiográficas, se encuentra condicionada por un preguntar históricamente a las "cosas mismas" el camino a seguir en el proceso de exploración de lo realmente acaecido.

La búsqueda de verificación, a la que se apunta con la pregunta histórica, solía denominarse en griego apodeixis. Se trata de un concepto que designa una búsquedadirigida, en la cual aquello que se procuran son respuestas preguntando a las cosas. Por eso es que Droysen llegó a afirmar que "[c]uando se sabe preguntar a las cosas, ellas dan la respuesta. La apodeixis muestra lo que se ha sabido buscar" (1983 [1937], 
§19, p.49. Cursivas propias). En el caso de la crítica de Ginzburg al principio jurídico unus testis, como bien se puede ver, la apodeixis permanece intacta, pues un correcto interrogatorio a cualquier testigo, por único que sea (unus testis), debería poder guiar al historiador en su desciframiento del pasado, principalmente porque el testigo (único o múltiple) parece siempre trazar los límites del horizonte interpretativo del historiador. A diferencia del derecho, en Historia se tiene por principio respetar y escuchar la voz del testigo único, en tanto que ella puede resultar decisiva para el des-ocultamiento del pasado.

No obstante, solo recientemente parece estarse intentando recuperar aquella tradición historiográfica iniciada en el siglo XIX por autores como Droysen y Leopold Von Ranke, pues fue en el siglo XX cuando la investigación de Michel De Certeau abrió la reflexión sobre el lugar del historiador en el relato histórico, y contribuyó considerablemente a seguir ampliando el horizonte teórico en torno a la investigación histórica hasta desbordarlo de una manera inimaginable. El problema real fue aquello que permitió sustentar este tipo de aportes teóricos en torno a la situación del investigador, dado que en ellos el historiador detrás del relato cobra un protagonismo inigualable, lo cual derivó en una particular forma de constructivismo radical que atenta contra el principio de realidad que por mucho tiempo guió a los esfuerzos historiográficos.

Incluso Robert Faurisson llegó a crear su famoso argumento revisionista, el cual supuestamente "desmiente" la existencia de campos de concentración en la historia de la Gran Guerra, montado sobre la reflexión de De Certeau. La idea de que el historiador es creador de discurso y artífice de la historia parecía permitirle fundamentar un argumento de ese calibre. Debido a esto, Pierre Vidal-Naquet, cuya madre había muerto en un campo de concentración a manos de los nazis, se vio en la obligación de recuperar el principio de realidad histórica planteado por Leopold Von Ranke, para fundamentar una extensa y disciplinada investigación que desmiente el argumento de Faurisson. De Certeau, al ver la reacción de su colega y amigo Vidal-Naquet contra la "investigación" de Faurisson, le escribió inmediatamente una carta fraternal en la que le decía que la realidad está más acá del discurso y, por ende, lo limita (Ginzburg 2014b, pp.304-6).

Al tiempo que se presentaban estos sucesos, la obra de De Certeau ejercía una gran influencia sobre el teórico norteamericano Hayden White; y no cabe duda que fue este último quien terminó estableciendo la piedra de toque que conduciría hacia el problema de la relativización del principio de realidad en el marco de la historiografía. Con eso, el propio White se alejaba inclusive de uno de los pensadores que él más admiraba: Benedetto Croce (Ginzburg 2014b, pp.306-9).

Fue en Tropics of Discourse donde el teórico norteamericano asumió la postura radical de Giovanni Gentile, quien afirmó que la historiografía crea el objeto al cual se refiere, es decir, crea el pasado (Ginzburg 2014b, p.313). En la misma obra, no 
obstante, el autor refleja el pensamiento exacerbado de los años sesenta y setenta, según el cual - políticamente hablando - la realidad está ligada a las ideologías de derecha; mientras que el deseo está ligado a las ideologías de izquierda (Ginzburg 2014b, p.316). En consecuencia, aquello que aparentemente debe ser detonado, desde las investigaciones académicas, es el principio de realidad que no permite abrir paso a deseos resumibles en ideales de igualdad, mejoría o plenitud.

Empero, este tipo de sesgos ideológicos lo único que le dejó a la teoría de la historia fue una alteración del concepto de verdad que dificulta la posibilidad de explorar el pasado responsablemente: reemplazó el concepto de verdad-probada, que guiaba tradicionalmente toda investigación histórica, por el concepto de verdad-eficaz, muy popular en el marco de la teoría literaria, donde el lenguaje crea mundos que deberían ser comprendidos en sus propios términos. ${ }^{11}$

Como se puede evidenciar en los postulados de Carlo Ginzburg, la verdad en Historia siempre había sido definida como verdad-probable, y su alcance seguía procedimientos similares a los de prácticas como el derecho; aunque con algunas alteraciones de los principios básicos de la jurisprudencia, como bien lo ejemplifica la crítica de Ginzburg al principio unus testis. Sin embargo, con la consolidación y popularización del pensamiento de White, la noción de verdad-eficaz emergió como una rara alternativa para la comprensión del pasado que se distanciaba considerablemente del principio de realidad defendido por Droysen y Ranke (1973, pp.39-44).

Ahora bien, la conexión hecha por White entre verdad y eficacia derivó en algo bastante problemático, si se lee desde la óptica del realismo hermenéutico: la verdad puede reducirse a una cuestión de qué versión sobre el mundo resulta más creíble, y ello termina siendo particularmente peligroso si tenemos presente un ejemplo radical ya planteado, este es, el intento de negacionismo del holocausto llevado a cabo por Robert Faurisson, que demuestra que la noción de verdad-eficaz es un atentado a un principio de suma importancia para la teoría histórica, como es el caso del principio de realidad que garantiza la responsabilidad en el proceso investigativo.

Desde la postura teórica de White, resulta posible afirmar que el único problema del relato de Faurisson es que no alcanzó la eficacia suficiente, no resultó lo suficientemente creíble, para consolidarse como verdadero y construir realidad. Como si la idea de negar el Holocausto no resultara reprochable en sí misma; sino tan solo ineficaz...

No obstante, al respecto, Ginzburg encuentra algo por lo demás bastante interesante: desde la teoría whiteana, potencialmente apta para fundamentar el revisionismo de Faurisson, lo único que podría reconocerse como el sustento de los relatos que denuncian las atrocidades nazis, durante la Segunda Guerra Mundial, es el hecho de que exista el Estado de Israel.

En ese sentido, la óptica whiteana permite ver a Israel como una suerte de monumento que conmemora el triunfo del relato de los judíos que sobrevivieron al Holo- 
causto. Sin embargo, esto lo único que quiere decir es que la versión judía sobre los campos de concentración tuvo más eficacia que otras versiones, como la de Faurisson. Pero, si esto es así, entonces de allí podría seguirse una afirmación no menos absurda que los argumentos que niegan los reprochables acontecimientos del genocidio judío: si Palestina sigue bajo el yugo israelí, eso es porque aún no ha sido elucubrada una verdad-eficaz por la vía pro-palestina que supere la verdad-eficaz judía que conllevó a la creación del Estado de Israel. Y esta hipótesis es sencillamente repudiable, irresponsable y digna de todo reproche, pues puede sustentar prácticas tan violentas como la famosa "filosofía del garrote", ${ }^{12}$ defendida por autores como Giovanni Gentile durante la cimentación del fascismo en Italia (Ginzburg 2014b, pp.319-21). Gentile, un autor que - como se ha mostrado con antelación - era profundamente admirado por Hayden White.

\subsection{Giro lingüístico y realismo hermenéutico}

En el trasfondo del problema de la perspectiva de White descansa el clásico debate entre lenguaje y realidad, escritura e historia, que deriva en la búsqueda por el desciframiento de la ideología que precede al texto histórico y que, por tanto, lo condiciona. En ese sentido, el teórico holandés Frank Ankersmit (2011, p.100) acierta al afirmar que uno de los grandes caminos abiertos por la teoría literaria, para la teoría de la historia, fue aquel que conlleva hacia el estudio de la escritura misma de los textos históricos, con la finalidad de descifrar su intención. Sin embargo, el propio Ankersmit reconoce que existe una gran diferencia entre teoría literaria y teoría histórica.

En la teoría literaria, el texto histórico aparece como la realidad. Esto es así porque en las perspectivas teórico-literarias la realidad descansa siempre en los textos estudiados: los textos son la realidad. En ese sentido, la brecha existente entre lenguaje y realidad no es propiamente un problema que preocupe a las teorías literarias; de esto se encargan, más bien, disciplinas como la epistemología o la filosofía del lenguaje (Ankersmit 2011, p.93). Sin embargo, existe un prejuicio básico que comparten tanto la teoría literaria como la vertiente del giro lingüístico defendida por Ankersmit (2011, p.92), y que incluso es un prejuicio que el realismo hermenéutico acepta sin problema alguno, a saber: que el lenguaje no es una suerte de "espejo" de la realidad y, por consiguiente, la realidad-representada (acercada-al-lector) ${ }^{13}$ se encuentra signada por el medium lingüístico empleado para su formulación textual.

Empero, la diferencia entre estas tres posturas es que, a diferencia de la teoría literaria que considera que el lenguaje - materializado en el texto - es una realidad en sí misma, y del giro lingüístico de Ankersmit (2011, p.95) que considera que el lenguaje incide en las creencias verdaderas sobre la realidad determinarla; el realismo hermenéutico, como ya se mostró en la primera parte de este arículo, se niega a 
privilegiar el potencial del lenguaje por sobre la realidad. Y esto último es decisivo al momento de intentar defender una teoría histórica realista capaz de dar cuenta del proceder historiográfico adecuado, es decir, capaz de dar cuenta de la investigación histórica como una práctica intelectual responsable.

Pero ¿qué es propiamente teoría de la historia, entonces? Ankersmit (2011, p.98) la define a partir de una diferenciación con la teoría literaria: si la teoría literaria se preocupa por cómo buscar significados ocultos en los textos históricos, mediante el estudio puramente lingüístico de los mismos; la teoría histórica se preocupa por cómo se debería representar, en los textos históricos, una realidad que es ajena a la realidad presente, es decir, la realidad pasada.

Esta definición de la teoría de la historia resulta interesante viniendo de Ankermit por al menos tres razones: 1) porque se adapta a lo que el realismo hermenéutico considera que debe ser una teoría histórica, 2) porque la noción de verdad de Ankersmit contrasta radicalmente con la noción de verdad del realismo hermenéutico, y 3) porque la teoría histórica así definida exige una fundamentación más propia del realismo hermenéutico que del giro lingüístico.

Primordialmente, entonces, es posible observar que la definición que ofrece Ankersmit, sobre la teoría de la historia, es lo suficientemente amplia como para permitir una afirmación que sostiene que una teoría histórica adecuada debe respetar el principio de realidad, y considerarlo como el punto de partida para toda re-presentación del pasado por la vía textual. La historia de los conceptos, entendida como una postura hermenéutica útil para el abordaje del pasado, en ese sentido, se erige como un buen ejemplo de búsqueda responsable por descifrar la realidad pretérita.

Fueron Gadamer y Koselleck los primeros en preocuparse recientemente por el desciframiento responsable del pasado por la vía lingüística, una vez que Gadamer (2015a, p.92) rescatara algunos de los postulados básicos de Aristóteles que descansan en el pasaje gamma de la Metafísica. Sin embargo, fue Koselleck quien trasladó los postulados histórico-conceptuales de la hermenéutica filosófica a la disciplina histórica, con la pregunta que cuestiona ¿cuál es la naturaleza de la relación temporal entre conceptos y situaciones o circunstancias? En respuesta a esta pregunta decisiva para los estudios histórico-conceptuales, Koselleck llegó a señalar que, sin duda alguna, "cualquier cosa que pueda y deba ser conceptualizada se encuentra fuera de los conceptos" (2004, p.30).

Con esta consigna de carácter realista, el historiador alemán elaboró una importante sentencia sobre la relevancia del principio de realidad para las investigaciones históricas, pues mostró que la única manera de llegar a reconstruir el pasado textualmente, sin tergiversarlo irresponsable y peligrosamente, es a través de una correcta reconstrucción conceptual. En consecuencia, siempre será necesario "desandar el camino desde la palabra conceptual [palabra artificial] a la palabra del lenguaje [palabra ordinaria] y rehacer el camino de la palabra del lenguaje a la palabra conceptual" 
(Gadamer 2015a, p.93), si aquello que se busca es una adecuada aproximación al pasado.

Ahora bien, es preciso tener en cuenta que lo cierto es que "el significado y el uso de una palabra nunca establece una relación de correspondencia exacta con lo que llamamos la realidad. Ambos, conceptos y realidades, tienen propias historias que, aunque relacionadas entre sí, se transforman de diversas maneras" (Koselleck 2004, p.36). De ahí la conclusión de que el lenguaje no es, en lo más mínimo, una especie de "espejo" de la realidad. Por tanto, la brecha entre lenguaje y realidad, aunque se logre solventar un poco mediante un adecuado proceder historiográfico, no queda nunca cerrada completamente bajo circunstancia alguna.

Es en este eterno forcejeo, entre desciframiento humano de la historia y tendencia al ocultamiento del pasado, donde descansa la naturaleza y el reto de la disciplina histórica, en sentido amplio, y de la teoría histórica, en sentido específico, puesto que aún las re-construcciones y re-presentaciones más fidedignas de algunos aspectos del pasado no cierran jamás las posibilidades de interpretación en torno al mismo. Después de todo, ninguna comprensión llega a ser alguna vez totalmente acabada (Heidegger 2014 [1927], §32, pp.170-1), y es por esa razón que el testigo, por único que sea, cobra tanta importancia para la historiografía.

Sin embargo, a partir de todo lo mencionado en estos últimos párrafos, surge otro cuestionamiento: si bien la definición de teoría histórica, proporcionada por el giro lingüístico de Ankersmit, ha permitido llegar a estos postulados hermenéuticos sobre la manera como puede procederse para alcanzar una correcta representación lingüística de la historia, ¿cómo se distancian, entonces, el giro lingüístico y el realismo hermenéutico? Una resposta a esta pregunta puede plantearse a partir de una comparación de las nociones de verdad en las que se apoyan cada una de las mencionadas posturas.

Como ya se presentó en la primera parte de este artículo, la aletheia (mostración) es la forma básica de la verdad recuperada por la teoría hermenéutica, y una de las formas derivadas de aletheia es la verdad por correspondencia aristotélica que tiempo después recuperó Tomás de Aquino para sus investigaciones teológico-filosóficas. En el giro lingüístico de Frank Ankersmit, sin embargo, la noción de verdad parece saltarse la forma originaria del fenómeno y asumirlo en su sentido puramente aristotélico-tomista derivado. Esto último termina generándole algunos serios problemas a la cimentación teórica del giro lingüístico llevada a cabo por Ankersmit.

Por un lado, el teórico holandés empieza su texto "Giro lingüístico, teoría literaria y teoría histórica" con una distinción entre el empirismo y el giro lingüístico que parte de la reconstrucción de los tipos de verdad propios del empirismo, a saber, las verdades sintéticas y las verdades analíticas. Las primeras son aquellas que se basan en los hechos (específicamente en los hechos-sensibles); y las segundas son las que se basan en significados independientes (significados artificiales, como en la lógica) 
(Ankersmit 2011, p.52). A partir de esta reconstrucción de los postulados del empirismo, Ankersmit (2011, p.53) llega a sostener que la diferencia entre éste y el giro lingüístico es que el último toma como creador de verdad tanto al lenguaje como a la realidad, lo que sugiere que el empirismo suele dejar por fuera de sus preocupaciones al lenguaje (al menos al lenguaje ordinario, cotidiano).

En este punto particular la postura de Ankersmit se distancia radicalmente del realismo hermenéutico, donde realidad y verdad son dos nociones equiparables, tal y como se mostró en el primer segmento de esta investigación. En consecuencia, no es nada sorprendente que el holandés crea que, dado que el historiador plantea sus propios criterios para presentar el pasado, la verdad no es - a su juicio - lo que regula lo afirmado por el historiador; sino que, más bien, se trata de aquello que está en juego cuando éste, el historiador, presenta su perspectiva sobre el pasado (Ankersmit 2011, p.57).

La afirmación de Ankersmit no sorprende sencillamente porque este autor parece saltarse el sentido originario de la verdad (aletheia), para presuponer que la verdad por correspondencia ha sido siempre el camino más importante para entrar en el debate sobre lo que significa que algo sea verdadero o no. Sin embargo, al salatarse el sentido originario de verdad, el holandés quita una base del único regulador de lo que puede o no ser afirmado de manera responsable, es decir, quita una base del principio de realidad que le permite ser un regulador de la investigación histórica.

Por otro lado, de hecho, cuando Ankersmit (2011, pp.60-1) acude al ejemplo del Renacimiento en su artículo, para mostrar que una definición supuestamente adecuada de ese período puede fundamentarse con una estructura lógica que sustente el criterio básico según el cual el historiador define el término "Renacimiento", llega a sostener que lo que está en juego en ese tipo de procedimiento narrativo no es propiamente la verdad; sino "las verdades" que pueden resultar útiles para aprehender el período en cuestión. Con esto, Ankersmit no pudo haber entrado a un terreno más pantanoso. El mismo pantano en el que ya White se había aventurado en su momento.

\subsection{Peligros del giro lingüístico y de la teoría literaria para la teoría histórica}

En términos generales, la tesis de Ankersmit es que no se debe apelar a la verdad (por correspondencia) para dar cuenta de la racionalidad histórica, puesto que el éxito de cualquier verdad radica en su utilidad y su presentación (lingüística). Este presupuesto parte de los postulados del giro lingüístico, en donde se asume que es en el lenguaje en donde se encuentra el camino para discernir entre verdades relevantes e irrelevantes (2011, pp.90-1).

Sin embargo, la crítica a Hayden White elaborada por Carlo Ginzburg lo que 
hace es precisamente mostrar que, al entender la verdad en términos de eficacia o de utilidad, de relevancia o de irrelevancia, lo único que se logra es relativizar el principo de realidad necesario para cualquier investigación histórica responsable, o lo que es lo mismo: para cualquier investigación sobre el pasado que no altere los acontecimientos, ni emplee dichas alteraciones para fines de cualquier índole.

Existen diversos ejemplos para mostrar lo que sucede cuando se le confía la historia, el pasado, a la verdad-eficaz. El de Robert Faurisson ya citado es solo uno de ellos. Ciertamente, acudir también a ejemplos en contra-vía de los casos de falseabilidad histórica será una tarea necesaria para el siguiente apartado, donde se mostrará la importancia del realismo para la teoría histórica. Pero por ahora bastará con señalar que la vuelta de Ankersmit al concepto de verdad-eficaz whiteano, con el fin de reemplazar el concepto de verdad-probada (o verdad por correspondencia) de la teoría histórica defendida por autores como Ginzburg, tan solo termina perjudicando al quehacer historiográfico, donde lo importante no es convencer; sino mostrar el pasado a través del lenguaje. Y esta es una tarea que poco o nada se preocupa por la calidad poética de los enunciados o por la maestría literaria en la construcción textual.

Por lo demás, es claro que Ankersmit tiene razón en algo muy importante: la realidad no nos brinda criterios para que podamos representarla (2011, p.67); pero de esto no se sigue que la realidad se adapte siempre a las representaciones que hacemos de ella. Esto es lo que sustenta la necesidad de discenir entre lo verdadero y lo falso en término realistas, es decir: entre lo real y lo irreal. Pero ¿cómo es posible este discernimiento en el marco de la práctica historiográfica? La respuesta parece estar dada ya en la tradición de la teoría histórica previa a los aportes de Michel De Certeau: por medio de la recavación y crítica de fuentes que nos aproximan al pasado.

Como ya se ha señalado antes, la realidad histórica muchas veces suele resistirse a nuestras formas de re-presentación, exigiéndonos respetar un criterio de verdad por correspondencia, de verdad-probada. De lo contrario, la representación, en la medida en que es siempre acerca-de-algo, como la define Ankersmit, puede perder todo su sentido básico y convertirse en un hablar-por-hablar, en donde mentir fácilmente puede llegar a equipararse con decir la verdad.

Por esta última razón, la fuente (sea el documento o el testimonio personal y vivo) es la materia prima del historiador y a la vez la materialización de que todo conocimiento sobre el pasado es, como sostenía Marc Bloch, "forzosamente «indirecto»" (2001 [1949], p.75). Empero, cuando se habla de "fuentes" se hace referencia también - y sobre todo - a un importante puente que permite avanzar hacia la exploración de la historia: solo a partir de la recavación de fuentes y su revisión crítica es que resulta posible determinar la diferencia entro lo ocurrido y lo no-ocurrido en el pasado, lo real y lo irreal.

Esta noción de las fuentes como un primer puente hacia el desciframiento de la 
historia se relaciona estrechamente con la noción hermenéutica del lenguaje como el primer puente hacia la comprensión. La diferencia entre ambas nociones, en realidad, es que la segunda resulta mucho más originaria que la primera, en tanto que las operaciones de recavación y crítica documental o testimonial son momentos de la comprensión del pasado al que solo los interesados en la escritura de la historia (historiografía) llegan.

No obstante, cabe preguntarse lo siguiente: si los teóricos literarios se preocupan también por la escritura de la historia, ¿no quiere esto decir que se preocupan a la vez por las fuentes que permiten el relato histórico? Siguiendo a Hayden White muy de cerca se podría afirmar que, más que preocuparse por las fuentes, los teóricos literarios se preocupan por el uso que hacen de ellas quienes escriben sobre el pasado.

A juicio de White (2003, p.191), siempre es posible evaluar los relatos con base en un marco realista, en donde pueden distinguirse los acontecimientos traducidosa-hechos de los hechos-farsa; aunque - y esta es la tesis base de su perspectiva todo relato histórico tiene también siempre una estructura literaria que lo distingue.

Hasta aquí, el realismo hermenéutico aceptaría la perspectiva whiteana, e inclusive vería en ella alguna preocupación sincera por las fuentes. El problema empieza cuando White (2003, p.199) intenta sostener que el tipo de relato define los hechos a narrar, pues ningún historiador procede de esa manera. Por el contrario, los historiadores parecen definir el tipo de relato dependiendo de los hechos que deben narrar, que están en la obligación de narrar si tales hechos resultan verdaderos en sentido realista-hermenéutico, es decir: reales. Con esta crítica a los presupuestos whiteanos se abre toda una oportunidad teórica para la historia.

Según el giro lingüístico de Ankersmit (2011, pp.103-5), por un lado, cuando la teoría literaria de White convierte el lenguaje histórico en una parte del mundo logra algo muy interesante, pero ello no nos enseña nada acerca de cómo este lenguaje se relaciona con ese mundo (exterior). De ahí que el giro lingüístico se preocupe tanto por esa relación lenguaje-mundo que permanece abierta aún en nuestros días. Por otro lado, si bien la teoría literaria es muy útil para estudiar las diversas formas de escritura de la historia; nada dice sobre cómo se debería representar el pasado y, cuando ha intentado dar su opinión al respecto, ha derivado en una filosofía especulativa sobre el pasado, como puede evidenciarse claramente en la obra de White cuando afirma que el relato determina los hechos a narrar.

En ese orden de ideas, es posible plantear una tesis que afirme que una correcta representación del pasado pasa por una adecuada exploración y crítica de las fuentes que acerquen al lector a la realidad del pasado. Pero esto ya lo había visto Ginzburg (2014a, pp.42-3 y 49-50) con gran precisión, cuando trazó una suerte de historia del relato histórico que lo llevó hasta el siglo XVI, a la época en que Sperone Speroni introdujo la posibilidad de utilizar discursos ficticios para ornamentar el relato histórico, con la condición de que se indicara por medio de comillas que el discurso 
introducido era falso. Por esa misma época aparecieron también las citas a la manera de un mecanismo mostrador del lugar donde se oculta la verdad.

Si se toman las citas como mostradoras de las fuentes empleadas en el relato histórico, esto es, como mostradoras del camino para llegar a determinar la verdad de lo narrado, entonces queda al descubierto el tipo de procedimiento que debe llevarse a cabo para escribir historiográficamente sin irrespetar el principio de realidad fundamentado por el realismo hermenéutico. Esa es la razón por la cual la citación crítica en Historia resulta ser un elemento tan importante de la investigación, pues es claro que "no son verídicos todos los relatos y las huellas materiales también pueden ser falsificadas" (Bloch 2001 [1949], p.97). Pero esto es algo que poco o nada preocupa a las posturas anti-realistas, donde la distinción entre hechos-verídicos y hechos-farsa, que determinan qué es histórico y qué no lo es, resulta irrelevante.

\subsection{Relevancia de una teoría histórica realista}

Teniendo presente el reto que implica mostrar la importancia de una teoría histórica realista, vale la pena centrarse en algunos breves ejemplos históricos que obligan a reflexionar antes de siquiera intentar negarlos. Los siguientes ejemplos son casos llamativos que pueden leerse desde la potencialidad de su carácter de acontecimientos límites. ${ }^{14}$

En el prólogo a los Reyes Taumaturgos, de Marc Bloch, Jacques Le Goff inicia con una frase contundente sobre el final de la vida de quien llegó a ser un maestro para, si no todos, casi todos los historiadores de Occidente: "Marc Bloch fue torturado por la Gestapo y fusilado a la edad de cincuenta y siete años el 16 de junio de 1944 en SaintDidier-de-Formans, Ain, cerca de Lyon, debido a su participación en la resistencia" (2006, p.11).

René Grousset, pone como epígrafe de su obra El Conquistador del Mundo la siguiente sentencia: "Dedico este libro a la memoria de Anatole Lewitzky, agregado del Musée de l'Homme, muerto por Francia el 23 de febrero de 1942, en Mont-Valérien" (2015, p.9. Cursivas originales).

Con base en estos enunciados y siguiendo de cerca lo acontecido durante la Segunda Guerra Mundial, la participación de Francia en algunos vejámenes contra la humanidad, y la cantidad de atrocidades que por cuenta del ser humano se han llevado a cabo a lo largo de la historia, ¿quién podría negar la verdad o realidad de lo afirmado por Le Goff y Grousset?

Sería posible citar en este segmento del artículo una cantidad inmensa de estudios que comprueban los acontecimientos contenidos en las sentencias anteriores, y este texto podría tomar otro rumbo fácilmente. Entonces, precisamente para evitar eso, cabe preguntarse por la relevancia del acontecimiento para la teoría histórica, con la finalidad de perfilar lo que sería la conclusión de este esfuerzo investigativo. 
El acontecimiento es la unidad mínima de significado para la historiografía de corte realista. Por medio de él, el historiador logra avanzar en la comprensión del pasado, descubrir aceleraciones y des-aceleraciones temporales, motivos humanos, señales del curso de la historia, y sobre todo prácticas e ideas que atraviesan al ser humano de antes y que en ocasiones se conservan en el de hoy.

En el pensamiento de Fernand Braudel, sin embargo, el acontecimiento parece estar estrechamente ligado a los "grandes destinos", a las "grandes personalidades" de seres humanos del pretérito que merecen atención dada la grandilocuencia de sus "incomparables" actos. De ahí que Braudel llegara a considerar a la unidad mínima de significado histórico en un sentido bastante negativo: "Los acontecimientos resonantes no son, con frecuencia, más que instantes fugaces, en los que se manifiestan estos grandes destinos [del pasado]" (1976 [1949], p.18).

Pero esta sentencia braudeliana, enunciada en el prólogo a la primera edición francesa de El Mediterráneo en tiempos de Felipe II (Vol. I), un clásico de la historiografía moderna occidental, no parece reconocer la importancia del acontecimiento en toda su dimensión y, al ser radicalizada por los sucesores de Braudel en la lucha contra la llamada "historiografía tradicional" de Ranke, derivó en una forma de desconocimiento o anulación de algunas cosmovisiones sobre el pasado.

El mejor ejemplo de una cosmovisión que resulta anulada o ignorada ante la perspectiva de Braudel y sus sucesores es la de la sociedad polaca. Al respecto, Robert Darnton ha presentado considerables apreciaciones en su texto «Dejen que Polonia sea Polonia», compilado en El beso de Lamourette.

La tesis central de ese texto es que en Polonia el "hambre de historia" es tan mordaz como el hambre-hambre, de alimento. Y esto es así porque la historia polaca se ha visto amenazada varias veces por cuenta de vecinos invasores o por cuenta, simplemente, de una minoría en el poder estatal del país. "Al ser un estado débil sin fronteras naturales, a Polonia quisieron repartírsela Rusia, Prusia y Austria en 1772, 1793 y 1795. En el siglo XIX sobrevivió como cultura gracias a sus poetas y su religión" (Darnton 2010, p.40).

A parte de estos intentos de invasión de finales del siglo XVIII, la Segunda Guerra Mundial abrió heridas tan profundas para la sociedad polaca que el hambre de historia se hizo aún más aguda. Nadie podría negar la sonoridad de los poetas o la fuerza motora de los representantes del catolicismo del siglo XIX polaco; pero tanto la poesía como la religión polacas se convirtieron en elementos mucho más ígneos de lo que solían ser antes de la Segunda Guerra Mundial.

Cuando Darnton visitó Polonia en la segunda mitad del siglo XX, el país ya había tenido que sufrir la invasión nazi liderada por Adolf Hitler, había pasado por la tragedia de que convirtieran su territorio en la sede principal de los campos de concentración más sanguinarios que ha visto la humanidad, y se encontraba al momento a la merced del régimen soviético, cuando el tema más abordado en la calles era el 
de la masacre de Katyn de 1940.

Sobre Katyn se decía que era un bosque donde un grupo de oficiales polacos fueron llevados y ejecutados a sangre fría, sin piedad y sistemáticamente, por alguna de las partes que se repartieron Polonia en 1940, es decir, por los nazis o por los soviéticos. Durante la estadía de Darton en Polonia, la historiografía oficial (la soviética) afirmaba que los nazis habían sido los autores de la masacre; mientras que la historiografía "clandestina" (la de la mayoría de los polacos) culpaba a los soviéticos (Darnton 2010, pp.42-3).

En aquel entonces, Darnton escribiría una preponderante reflexión acerca de la perspectiva polaca sobre la historia que, aún en en nuestros días, conserva una gran autoridad:

Hoy la fórmula rankeana parece apta y urgente en Polonia. Suena arcaica en Europa occidental, donde los historiadores de vanguardia la dejaron hace tiempo para estudiar el juego de la 'estructura' y la 'coyuntura' sobre la long durée. Estas fórmulas provienen de la escuela de los Annales, que decretó la muerte de la 'historia acontecimental', histoire événementielle: 'un cadáver que todavía debemos matar', en palabras de Jacques Le Goff, ex presidente de la VI sección de la École Pratique des Hautes Études en París" (Darnton 2010, p.49).

El intento incendiario de la Escuela de los Annales por encerrar el acontecimiento en la escala de los amplios períodos de análisis desemboca en un atentado no solo contra la unidad mínima de significado histórico; sino también contra cosmovisiones como la polaca, y contra la propia teoría histórica de carácter realista, pues constituye una ignorancia del hecho de que los cambios repentinos, rápidos y certeros, que tienen lugar en el tiempo, nada tienen que ver con lo "fugaz", como creía Braudel.

Lo cierto es que para los polacos hay una diferencia de vida o muerte (sobre todo de muerte) entre 1940 y 1941, y ello se debe a que las transformaciones históricas en su país se daban tan rápido que era cuestión de años, meses e incluso días, horas y minutos darse cuenta de cómo todo podía ser realmente destrozado de manera irreparable.

\section{Conclusión}

Con el caso polaco traído a colación, y con los otros ejemplos radicales que se tuvieron en cuenta a lo largo de este artículo, se observa que una buena manera de defender el realismo en la Historia es acudiendo a acontecimientos límites turbulentos, pues solo a través de ellos es que salta a la vista la importancia de narrar siempre lo realmente sucedido, una cuestión que se mueve tanto en los márgenes de la moral como en los de la epistemología. 
Sumado a esto último, se debe mencionar que una argumentación ordenada a favor del realismo en la Historia puede ser llevada a cabo - como se mostró - en dos momentos cardinales: 1) a través de una recuperación de los postulados realistas de la teoría hermenéutica (primera parte de esta investigación); y 2) a través del aprovechamiento de tales postulados en el debate entre teoría histórica y teoría literaria, un terreno en el que ya el giro lingüístico de Ankersmit había incursionado (segunda parte de esta investigación).

Al sacar a la luz los riesgos del anti-realismo para la Historia, ya se lograba exponer en este texto la relevancia de una teoría histórica realista. Sin embargo, fue necesario presentar algunos casos específicos en donde se percibe muy bien que el pasado es más que lo que se dice o se cree sobre él, pues ello no parece ser tan evidente en la actualidad. Esa fue la razón por la cual Gadamer llegó a aseverar que "la realidad no acontece «a espaldas del lenguaje», sino a espaldas de aquellos que pretenden comprender perfectamente al mundo" (2015c, p.237). De esto puede derivarse que la historia suele ocultarse, principalmente, detrás de quienes creen que ella no existe o que se trata de una simple invención humana.

\section{Referencias}

Ankersmit, F. 2011. El giro lingüístico: teoría literaria y teoría histórica. En: Giro lingüústico, teoría literaria y teoría histórica, pp.49-105. Trad. L. Cucchi \& J. Giglio [The Linguistic Turn: Literary Theory and Historical Theory. In: The Linguistic Turn, Literary Theory and Historical Theory]. Buenos Aires: Prometeo Libros.

Bhaskar, R. 1998. The Possibility of Naturalism. A Philosphical Critique of the Contemporary Human Sciences. Londres: Routledge.

Bloch, M. 2001 [1949]. Apología para la historia o el oficio del historiador. Trad. M. Jménez \& D. Zaslavsky [Apologie pour l'histoire ou Métier d'historien]. México: Fondo de Cultura Económica.

Braudel, F. 1976 [1949]. El Mediterráneo y el mundo mediterráneo en la época de Felipe II. Vol. 1. Trad. M. Monteforte, W. Roces \& V. Simón [La Méditerranée et le monde méditerranéen à l'epoque de Philippe II]. Madrid: Fondo de Cultura Económica.

Chartier, R. 2007. La historia o la lectura del tiempo. Trad. M. Polo [L'histoire ou lecture du temps]. Barcelona: Gedisa.

Darnton, R. 2010. Dejen que Polonia sea Polonia. En: El beso de Lamourette. Reflexiones sobre historia cultural, pp.39-49. Trad. A. Saborit, E. Rivas \& A. Ramos [Let Poland be Poland. In: The Kiss of Lamourette. Reflections in Cultural History] Buenos Aires: Fondo de Cultura Económica.

De Cusa, N. 2011 [1445]. La búsqueda de Dios. En: Diálogos sobre el Dios escondido/La búsqueda de Dios, pp.35-75. Trad. Á. L. González [De quaerendo Deum. In: De Deo abscondito/De quaerendo Deum]. Pamplona: Universidad de Navarra.

Descartes, R. 2011 [1641]. Meditaciones Metafísicas [CP]. Seguidas de las objeciones y respuestas. En: Biblioteca de Grandes Pensadores. Descartes, pp.153-413. Trad. J. A. Díaz [Co- 
gitationes Privatae]. Madrid: Gredos.

Dilthey, W. 1949 [1883]. Introducción a las Ciencias del Espíritu. Trad. E. Imaz [Einführung in die Geisteswissenschaften]. México: Fondo de Cultura Económica.

Droysen, J. G. 1983 [1937]. Histórica. Lecciones sobre la Enciclopedia y metodología de la historia. Trad. E. Garzón \& R. Gutiérrez Girardot [Historik. Vorlesungen über Enzyklopädie und Methodologie der Geschichte]. Barcelona: Alfa.

Estrada, C. 2018. La escucha como interpelación en el círculo hermenéutico. Tesis de Pregrado, Universidad del Rosario, Escuela de Ciencias Humanas, Bogotá.

Fustel de Coulanges, N.-D. 1997 [1863]. La Ciudad Antigua. Estudio sobre el culto, el derecho, las instituciones de Grecia y Roma. Trad. M. Cigés Aparicio [La Cité Antique. Etude sur le cult, le droit, les insitutions de la Grèce et de Rome]. Santafé de Bogotá: Panamericana.

Gadamer, H.-G. 2003. El problema de la conciencia histórica. Trad. A. Domingo [Das Problem des historischen Bewusstseins]. Barcelona: Tecnos.

Gadamer, H.-G. 1997. Histórica y lenguaje: Una respuesta. En: R. Koselleck, \& H.-G. Gadamer, Historia y Hermenéutica, pp.95-106. Trad. F. Oncina [Historik und Sprache: Eine Antwort]. Barcelona: Paidós.

Gadamer, H.-G. 2015a. La historia del concepto como filosofía (1970). En Verdad y Método II, pp.81-93. Trad. M. Olasagasti [Die Geschichte des Konzepts als Philosophie (1970). In: Warheit und Methode II]. Salamanca: Sígueme.

Gadamer, H.-G. 2015b. ¿Qué es la verdad? (1957). En Verdad y Método II, pp.51-62. Trad. M. Olasagasti [Was ist die Warheit? (1957). In: Warheit und Methode II]. Salamanca: Sígueme.

Gadamer, H.-G. 2015c. Retórica, hermenéutica y crítica de la ideología. Comentarios metacríticos a Verdad y Método I (1967). En Verdad y Método II, pp.225-241. Trad. M. Olasagasti [Rethorik, Hermeneutik und Ideologiekritik. Metakritische Kommentare zu Wahrheit und Methode I (1967). In: Warheit und Methode II]. Salamanca: Sígueme.

Gadamer, H.-G. 2012 [1960]. Verdad y Método I. Trad. A. Agud \& R. De Agapito [Warheit und Methode I]. Salamanca: Sígueme.

Ginzburg, C. 2014a. Descripción y cita. En El hilo y las huellas. Lo verdadero, lo falso y lo ficticio, pp.19-54. Trad. L. Padilla [Descrizione e citazione. In: Il filo e le tracce. Vero falso finto]. Buenos Aires: Fondo de Cultura Económica.

Ginzburg, C. 2014b. Unus Testis. El exterminio de los judíos y el principio de realidad. En El hilo y las huellas. En: Lo verdadero, lo falso y lo ficticio, pp.297-326. Trad. L. Padilla [Unus Testis. Lo sterminio degli ebrei e il principio di realtà. In: Il filo e le tracce. Vero falso finto]. Buenos Aires: Fondo de Cultura Económica.

Gómez Rincón, C. M. 2017. Historicidad, realismo y verdad. Principia 21 (1): 77-98.

Grousset, R. 2015. El Conquistador del Mundo. Vida de Gengis Kan. Trad. J. R. Monreal [Le Conquérant du Monde. La Vie de Gengis Kan]. Barcelona: Acantilado.

Habermas, J. 1996. La Pretensión de Universalidad de la Hermenéutica (1970). En La Lógica de las Ciencias Sociales, pp.277-306. Trad. M. Jiménez Redondo [Der Universalitätanspruch der Hermeneutik (1970). In: Zur Logik der Socialwissenschaften] Madrid: Tecnos.

Heidegger, M. 2014 [1927]. El ser y el tiempo. Trad. J. Gaos [Sein und Zeit]. México: Fondo de Cultura Económica.

Heráclito. 1983 [1903]. Fragmentos. En Parménides-Zenón-Meliso-Heráclito (Escuela de Elea). Fragmentos, pp.191-250. Trad. J. A. Miguez [Die Fragmente der Vorsokratiker]. Barcelona: 
Orbis.

Kant, I. 2007 [1781]. Crítica de la Razón Pura [KrV]. Trad. M. Caimi [Kritik der reinen Vernunft]. Buenos Aires: Colihue.

Koselleck, R. 2004. Historia de los conceptos y conceptos de historia. Trad. J. Fernández Sebastián \& G. Capellán [Begriffigeschichte und Geschichtsbegriff]. Ayer. Revista de Historia Contemporánea 1 (53): 27-45.

Koselleck, R. 1997. Histórica y Hermenéutica. En R. Koselleck, \& H.-G. Gadamer, Historia y Hermenéutica, pp.65-94. Trad. F. Oncina [Historik und Hermeneutik]. Barcelona: Paidós.

Le Goff, J. 2006. Prólogo. En M. Bloch, Los Reyes Taumaturgos. Estudio sobre el carácter sobrenatural atribuido al poder real, particularmente en Francia e Inglaterra, pp.11-57. Trad. M. Lara \& J. C. Rodríguez [Préface. Dans: Les Rois Thaumaturges. Étude sur le caractére surnaturel attribué à la puissance royale particulièrement en France et en Angleterre] México: Fondo de Cultura Económica.

Mudrovcic, María Inés. 2007. El debate en torno a la representación de acontecimientos límite del pasado reciente: Alcances del testimonio como fuente. Diánoia 52 (59): 127-150.

Nietzsche, F. 2001 [1873]. Verdad y mentira en sentido extramoral. Trad. E. López [Über Wahrheit und Lüge im aussermoralischen Sinne]. Cuaderno Gris 3 (5): 227-237.

Ranke, L. Von. 1973. On the Character of Historical Science (A Manuscript of the 1830s). En: G. G. Igger y K. Von Moltke (Eds.), The Theory and Practice of History, pp.33-46. Trad. W. Iggers [Idee der Universalhistoire. In: Historische Zeitschrift]. Indinapolis: Bobbs-Merrill.

Sánchez Lopera, A. 2017. José Revueltas y Roberto Bolaño. Formas Genéricas de la Experiencia. Raleigh: A Contracorriente.

Smith, C. 2010. What is a Person? Rethinking Humanity, Social Life, and the Moral Good from the Person Up. Chicago: University of Chicago Press.

White, H. 2003. La trama histórica y el problema de la verdad en la representación histórica. En: El texto histórico como artefacto literario, pp.189-216. Trad. V. Tozzi \& N. Lavagnino [The historical plot and the problem of truth in historical representation]. Barcelona: Paidós.

White, H. 1975. Metahistory. The Historical Imagination in the Ninteenth-Century Europe. Baltimore and London: The Hopkins University.

White, H. 1990. Tropics of Discourse. Essays in Cultural Criticism. Baltimore: John Hopkins University Press.

\section{Notas}

${ }^{1}$ En este artículo se emplea la palabra "Historia", con mayúscula al inicio, para hacer referencia a la disciplina histórica, a la práctica de investigación histórica como tal. Con esto se distingue a dicha disciplina de su objeto de estudio: el pasado o "historia", con minúscula al inicio.

${ }^{2}$ Alejandro Sánchez Lopera, en su reciente tesis doctoral titulada José Revueltas y Roberto Bolaño. Formas Genéricas de la Experiencia (2017, pp.107-32), ha hecho gran énfasis en la necesidad de evitar a toda costa que se llegue al extremo de homologar el acontecimiento por lo que se dice del acontecimiento. A partir de un lúcido estudio sobre la desaparición parcial de la realidad mexicana de los años sesenta, en el marco de algunas obras sobre esa 
época y ese contexto, Sánchez advierte acerca de los peligros de privilegiar el lenguaje sobre la realidad, en un sentido general, y de privilegiar la literatura sobre la historia, en un sentido más específico.

${ }^{3}$ Con esta expresión se hace referencia a las investigaciones que se situan en el ámbito originario de las llamadas Ciencias del Espíritu, las cuales nacieron en el siglo XIX y se concentraban en campos como el de la historia, la jurisprudencia y la economía (Dilthey 1949 [1883], Prólogo, pp.4-5). Sin embargo, como las denominadas Ciencias Sociales contemporáneas surgieron sobre las bases dejadas por las Ciencias del Espíritu, con la expresión "científico-espiritual" también se hace referencia a las investigaciones nacidas en campos como los de la geografía, la antropología, la sociología, etcétera. Se ha buscado más es la conservación de un término clásico muy abarcativo.

${ }^{4}$ The Possibility of Naturalism. A Philosophical Critique of the Contemporary Human Sciences, de Roy Bhaskar (1998, pp.88-125), y What is a Person? Rethinking Humanity, Social Life and Moral Good from the Person Up, de Christian Smith (2010, pp.119-206), son excelentes muestras de perspectivas contemporáneas volcadas a la defensa y fundamentación del realismo filosófico a partir del fenómeno del emergentismo y de la agencia.

${ }^{5}$ En la argumentación de De Cusa puede leerse: "Sed intellectuales naturae pariformiter non possunt negare regem sibi praeponi" [Las naturalezas intelectuales no pueden negar que por encima de ellas tiene la preeminencia un rey] (2011 [1445], I, pp.44-5. Traducción de Ángel Luís González). Por rey que rige el intelecto, De Cusa se refiere al Dios supremo de la doctrina cristiana.

${ }^{6}$ En su texto de juventud "Verdad y mentira en sentido extramoral", Nietzsche deja muy clara su definición de verdad relacionada con la potencia creadora del ser humano: "las verdades son ilusiones [creadas por los humanos] cuyo carácter ficticio ha sido olvidado" (2001 [1873], I, p.231).

${ }^{7}$ La exigencia kantiana de la comprobación del mundo exterior obedece a un meta-principio establecido por el propio Immanuel Kant: "todos los conceptos y, con ellos, todos los principios, por mucho que sean a priori, se refieren a intuiciones empíricas, es decir a data para una experiencia posible. Sin esto no tienen ninguna validez objetiva, sino que son solo un mero juego, sea de la imaginación, sea del entendimiento, con las respectivas representaciones" (KrV 2007 [1781], A239, p.332). A partir de este meta-principio, la comprobación por la "vía data" del mundo exterior resulta indispensable para el pensamiento, según Kant. (Es necesario mencionar que se ha empleado la citación tradicionalmente aceptada por los especialistas en la obra de Kant, donde " $\mathrm{KrV}$ " indica que se está citando la Kritik der reinen Vernunft [Crítica de la Razón Pura], "A239" indica que se está citando el paginado de la primera edición de la obra [A], y "p.332" es el número de la página específica de la edición de la obra que se ha empleado en el marco de este artículo, esta es, la preparada por Mario Caimi para la editorial Colihue de Buenos Aires en 2007).

${ }^{8}$ Se ha seguido el sistema de citación tradicionalmente empleado por los especialistas en la obra de René Descartes. En dicho sistema, las siglas " $C P$ " se refieren a las iniciales del nombre original de las Meditaciones Metafísicas: Cogitationes Privatae. Seguidamente se señala que se ha citado la "Primera Meditación" del tratado. Luego, se han escrito las siglas "A-T" para especificar que se ha seguido la compilación de obras de Descartes llevada a cabo por Charles Adam [A] y Paul Tannery [T]: Ouvres de Descartes [Obras de Descartes], París, Vrin, 18971913. Continuamente, se destaca que se ha empleado el tomo IX de las Ouvres. Y finalmente, 
se destaca que se cita exactamente la página 169 de la edición de la obra aquí empleada, cuya traducción y preparación fue efectuada por Jorge Aurelio Díaz para la editorial Gredos de Madrid.

${ }^{9}$ Se ha empleado la citación tradicionalmente aceptada por los especialistas en la obra de Heráclito. En dicha citación, las siglas "D-K" se refieren a las iniciales de los apellidos de Hermann Diels y Walther Kranz, quienes realizaron la compilación y traducción más completa, meticulosa y responsable de los fragmentos de la mayoría de los filósofos que precedieron a Sócrates, de allí el nombre de su obra: Die Fragmente der Vorsokratiker [Fragmentos de los Presocráticos], Berlín, 1903. El 22 que sigue a la sigla es el número de autor correspondiente a Heráclito, según el sistema de organización de "autores presocráticos" establecido por Diels y Kranz. La letra "B" en la citación indica que se cita un fragmento y no un testimonio, en cuyo caso se emplearía la letra "A". Y el 123 es el número dentro del sistema D-K del fragmento que ha sido citado.

${ }^{10}$ Esto fue precisamente lo que le permitió a Numa-Denis Fustel de Coulanges llevar a cabo su investigación sobre la relación entre sociedades tan lejanas en el tiempo como la griega, la romana y sus predecesoras: toda marca en un tiempo determinado remite a situaciones que tuvieron lugar en tiempos previos. Al respecto, el autor afirmó: "Observemos a los griegos del tiempo de Pericles, a los romanos del tiempo de Cicerón: ostentan en sí las marcas auténticas y los vestigios ciertos de los siglos más distantes. El contemporáneo de Cicerón (me refiero singularmente al hombre del pueblo) tiene la imaginación llena de leyendas; esas leyendas provienen de un tiempo antiquísimo y testifican la manera de pensar de aquel tiempo" (Fustel de Coulanges 1997 [1864], Introducción, pp.XIV-V).

${ }^{11}$ En la que puede considerarse como una de sus obras más destacada, si no la más, White deja bastante claro que muchos de los llamados "textos clásicos" de historiografía lo son debido a la "consistencia, coherencia y poder iluminativo de sus respectivas visiones sobre el campo histórico [pasado]". Por tanto, añade, "su estatus como modelos de narración histórica y conceptualización depende, en últimas, de [su] naturaleza preconceptual y específicamente poética" (White 1975, p.4. Traducción Libre del Autor). Con esto White termina por otorgarle toda la atención al lenguaje, privilegiándolo sobre la realidad. Esa es una postura que la hermenéutica estaría dispuesta a confrontar por medio de su propia concepción de lo clásico como un puente hacia la verdad, pues la elocuencia de lo clásico es tan ilimitada que habla y descubre verdad tanto en su tiempo como en cualquier otro tiempo (Gadamer 2012 [1960], pp.353-60).

${ }^{12}$ La llamada "filosofía del garrote" señala que el único orden moral posible es el que establece el Estado por medio de la fuerza pública. Por ende, cuando el Estado entra en crisis, su representación por excelencia, en términos gráficos, puede ser reducida a la figura de un garrote: una herramienta creada para golpear. En el contexto del fascismo italiano, se llegó a denominar a Gentile como el "filósofo del garrote", dado que él mismo contribuyó a fundamentar filosóficamente la ideología fascista impulsada por Benito Mussolini, donde la verdad del estado era la única verdad posible (Ginzburg 2014b, nota 51, p.318).

${ }^{13}$ Cuando Ankersmit habla sobre la manera como el lenguaje ordena el caos del pasado, emplea el concepto técnico de representación, el cual se refiere a una suerte de mecanismo para acercar-al-lector al pasado, mediante una composición lingüística adecuada a la realidad histórica; pero limitada o condenada a alcanzar tan solo unos aspectos de ella. La representación es, por tanto, una cuestión práctica previa a la descripción, al referirse-a-algo, que emerge 
en un nivel teórico incluso más limitado (Ankersmit 2011, pp.103-4). Sobre la limitación de la descripción frente a la representación, Ginzburg se ha pronunciado en un artículo titulado «Descripción y cita» (2014a, pp.29-30), allí el italiano muestra que el origen de la representación reposa en el universo de la retórica greco-latina, donde los momentos previos a la verdad son: a) relato histórico (representación), b) descripción, y c) vividez.

${ }^{14}$ Se emplea el concepto de acontecimiento límite en el sentido que le atribuye María Inés Mudrovciv, es decir, para hacer referencia a aquellos acontecimientos que "exceden los límites de la comprensión y la experiencia humana" (2007, p.131); pero que, de alguna manera, pueden ser abordados moral y epistemológicamente. 